\title{
Zunge zeigen nach Thrombolyse
}

— Eine 66-jährige Frau wurde wegen eines akuten Myokardinfarkts mit Aspirin, Clopidogrel, 10000 U Tenecteplase sowie $5000 \mathrm{U}$ unfraktioniertem Heparin behandelt. Eine Reperfusion der verschlossenen Koronararterie konnte nicht erreicht werden. Die Patientin unterzog sich daher einer perkutanen Angioplastie der rechten Koronararterie.

Sechs Stunden nach dem Eingriff berichtete die Patientin über ein brennendes Gefühl in der Zunge. Bei der Untersuchung sah man eine ausgedehnte, scharf begrenzte blauschwarze Verfärbung der Zungenunterfläche. Dieser Befund war vereinbar mit einem Zungenhämatom (Abb. A und B). Die Patientin hatte keinen Stridor, keine Dyspnoe, keine Dysphagie und keine Veränderung ihrer Stimme. Die intravenöse Gabe von Heparin wurde beendet,
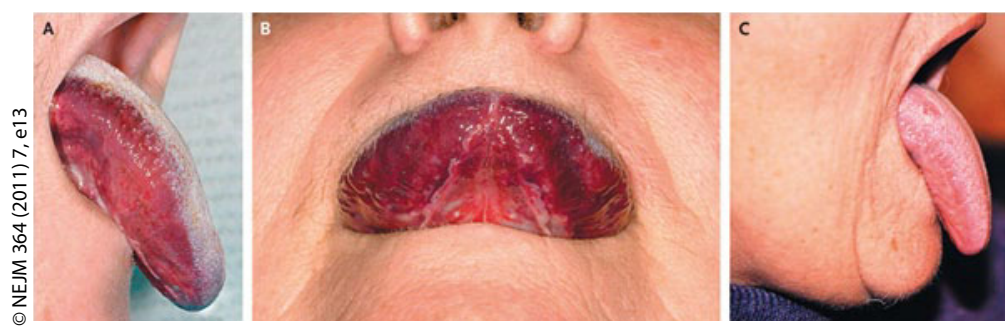

4 Zungenhämatom $(A+B)$ und Zustand nach wenigen Tagen (C).

die Therapie mit Aspirin und Clopidogrel aber fortgesetzt. Unter sorgfältiger Beobachtung bildete sich das Hämatom im Lauf von mehreren Tagen spontan zurück (Abb. C).

\section{Kommentar}

Naturgemäß stellen Blutungen eine bekannte und wichtige Komplikation einer thrombolytischen Therapie dar. Hämatome im Bereich der Zunge sind zum Glück sel- ten, können allerdings aus anatomischen Gründen lebensbedrohliche Verlegungen der Atemwege hervorrufen. Es empfiehlt sich daher, den Klagen von Patienten frühzeitig nachzugehen, routinemäßig die Mundhöhle zu inspizieren und im Falle eines Zungenhämatoms in Intubationsbereitschaft zu stehen.

H. S. FüESSL

- S. Vijayan, A. Chase (Korres.: Morriston Hospital, Swansea, Wales, UK; E-Mail: sethu@doctors. org.uk) Lingual hematoma after thrombolytic therapy. New Engl. J. Med. 364 (2011) 7, e13 